\title{
WHY STUDENTS DRINK: A STUDY OF SOUTH AFRICAN UNIVERSITY STUDENTS' DRINKING BEHAVIOUR
}

\author{
R. du Preez* \\ Department of Industrial Psychology \\ e-mail:Rdp@sun.ac.za
}

\section{D. Pentz*}

Department of Business Management

e-mail: cdpentz@sun.ac.za

\section{B. W. Lategan*}

Department of Business Management

e-mail:wihanl@gmail.com

*Stellenbosch University

Stellenbosch, South Africa

\section{ABSTRACT}

Little is known about the drinking behaviour of South African university students and education and prevention campaigns are not necessarily based on scientific research results. To change drinking behaviour, it is important to address the drinking motives, alcohol outcome expectancies, and alcohol-related behaviour that hold valence in education and prevention campaigns. The purpose of this study was to gain insight into the drinking behaviour of South African university students, and to make recommendations towards the development of persuasive communications that will address drinking motives and alcohol outcomes. The measurement instruments used in the study included the Alcohol Use Disorder Identification Test (AUDIT), the Drinking Expectancy Questionnaire Revised (DEQ-R), and the Drinking Motives Questionnaire Revised (DMQ-R). Data $(n=474)$ were collected from university students from a single campus in South Africa. The data analyses included independent sample t-tests, ANOVA and partial least squares modelling. The results indicate that students expect an element of tension reduction and an increase in sexual interest when consuming alcohol and that they primarily drink for social and enhancement motives. The influence of positive alcohol outcome expectancies on drinking behaviour is mediated by social and enhancement motives. The study's findings can be used by universities to develop effective education and responsible drinking programmes.

Key words: drinking motives, alcohol outcome expectancies, drinking behaviour, university students, South African student drinking, alcohol consumption

\section{INTRODUCTION}


The negative impact of excessive alcohol consumption is well documented around the world. Globally, alcohol is the third largest risk factor for disease and disability and the eighth largest risk factor for death (Global Status Report on Alcohol and Health 2011, 31). In 2012, an estimated 5.9 per cent of global deaths and 5.1 per cent of the global burden of disease were attributed to alcohol (Global Status Report on Alcohol and Health 2014, 16). Moreover, alcohol consumption is reported to be responsible for more deaths than HIV/AIDS, violence or tuberculosis worldwide, and has been identified as a serious global health problem and priority, especially in middle-income countries such as South Africa (Global Status Report on Alcohol and Health 2011; Global Status Report on Alcohol and Health 2014, 46).

In 2000, an estimated 7.0 per cent of all deaths and 7.1 per cent of the burden of disease in South Africa were attributed to alcohol, which is significantly higher than the global averages (Schneider, Norman, Parry, Bradshaw, Pluddemann and South African Comparative Risk Assessment Collaboration 2007, 668). South Africa has also been identified by the World Health Organisation (WHO) as a country with a high per capita alcohol consumption, binge drinking, and risky and harmful drinking patterns (Global Status Report on Alcohol and Health 2011, 15, 17). It is thus evident that South Africa has a serious alcohol problem (Peltzer, Davids and Njuho 2011, 31). To compound the problem further, young South African adults seem to be more prone to high levels of alcohol consumption and alcohol-related problems.

On a global scale, it appears that hazardous and harmful drinking patterns such as drinking to intoxication and binge drinking are also increasing among adolescents and young adults. The WHO has identified alcohol to be the leading risk factor of deaths among 15-29 year old males, confirming in 2011 that 9 per cent of annual deaths in this age group were attributed to alcoholrelated causes (Global Status Report on Alcohol and Health 2011; Global Status Report on Alcohol and Health 2014, 28). Furthermore, Peltzer et al. (2011, 36) isolated young adults as having the highest levels of binge drinking, and harmful drinking patterns in South Africa. Drinking among young adults is thus understandably of great concern to the South African public health authorities and drastic policy changes have been proposed such as prohibiting alcohol advertising and a zero tolerance towards drinking and driving (Germishuys 2015; SAPA 2013 ).

University students, a sub-group of young adults, are characterised by heavier, more frequent, and even more dangerous drinking patterns than their non-student peers (Kypri, Cronin and Wright 2005, 713). Alcohol consumption and excessive drinking are often seen as being normal and part of the university experience. Although the drinking behaviour of North American university students is well documented (Hingson, Zha and Weitzman 2009, 19), 
limited research has been conducted into the drinking behaviour of South African university students.

Against this background, the purpose of this study was firstly to investigate the drinking motives and alcohol outcome expectancies of university students, and secondly, to make recommendations towards the development of persuasive communications that include educational and prevention campaigns to strengthen the cause against excessive alcohol consumption. Such efforts by university management can address the negative consequences students may experience as a result of excessive alcohol consumption.

\section{LITERATURE OVERVIEW}

Several antecedents of behaviour have proved to be reliable predictors of drinking behaviour, such as media consumption patterns, reference groups, culture, social drinking norms, sociodemographic indicators, alcohol knowledge, attitudes toward alcohol, alcohol outcome expectancies, and drinking motives. A hierarchical effect has been observed among the antecedents with the most proximal antecedents explaining the largest amount of variance in behaviour (Kong and Bergman 2010, 856). Thus, some antecedents are more significant than others in terms of explaining alcohol-related outcomes. Theorists argue that drinking motives and alcohol outcome expectancies - two interrelated antecedents - are the most proximal predictors of drinking behaviour that explain a large amount of the variance in the drinking behaviour of individuals (Cooper 1994, 127; Cox and Klinger 1988, 178). Together these antecedents account for more than 50 per cent of variance in the drinking behaviour of university students (Hasking, Lyvers and Carlopio 2011, 484), and were consequently used to investigate drinking behaviour in this study.

\section{Alcohol outcome expectancies}

Alcohol outcome expectancies are defined as the beliefs about the positive or negative, cognitive, affective and behavioural effects or outcomes of alcohol (Agrawal, Dick, Bucholz, Madden, Cooper, Sher and Heath 2008, 194). In other words, alcohol outcome expectancies are what the individual believes will happen when a specific amount of alcohol is consumed within a given period of time. The Social Cognitive Theory (Bandura 1977) has made a significant contribution towards the understanding of how alcohol abuse and dependence develop, and proposes that drinking behaviour is, in part, governed by beliefs related to the perceived consequences of alcohol consumption (Young and Oei 1993, 340). Moreover, the Expectancy Theory has emerged as a viable explanation for the link between alcohol outcome expectancies 
and drinking behaviour. According to this theory, an individual will decide to behave or act in a certain way because he or she is motivated to select a specific behaviour (over alternative behaviours) due to what he or she expects the outcome will be of that selected behaviour (Jones, Corbin and Fromme 2001, 59). Thus, it can be postulated that alcohol outcome expectancies play a key role in explaining and understanding the drinking behaviour of individuals.

Alcohol outcome expectancies can be divided into two broad categories, namely positive expectancies and negative expectancies. Positive expectancies refer to the belief that effects such as sociability and confidence are gained or enhanced by the consumption of alcohol, while effects such as affective distress are minimised. Negative expectancies, on the other hand, are the belief that consuming alcohol will have negative consequences such as physical fatigue or impaired cognition and judgement (Jones et al. 2001, 59). Studies in the field of alcohol outcome expectancies have identified specific patterns of positive and negative expectancies that are most likely to motivate alcohol use, and that may increase the risk of heavy consumption and alcohol-related problems.

Positive alcohol outcome expectancies have often been linked to the initiation of alcohol use, heavy drinking, the experience of negative alcohol-related consequences, alcohol use disorders, relapse, and other risk factors for negative alcohol outcomes including a family history of alcoholism (Brown, Goldman and Christiansen 1985, 516; Kilbey, Downey and Breslau 1998, 154; Pastor and Evans 2003, 211; Schuckit and Smith 2001, 4).

The results of the relationship between negative alcohol expectancies and drinking behaviour have been less consistent (and investigated less) than those of the relationship between positive alcohol expectancies and drinking behaviour (Morean, Treat and Corbin 2012, 1009). Negative alcohol expectancies have generally been associated with decreased alcohol consumption (Fromme and D’Amico 2000, 209; Jones et al. 2001, 62). However, negative alcohol expectancies have also been linked to increased alcohol consumption rather than decreased consumption (Greenfield, Harford and Tam 2009, 84; Pabst, Baumeister and Kraus 2010, 49). This ambiguity may be attributed to the numerous ways in which alcohol expectancies have been measured, or the negative effects that are believed to accompany excessive drinking, such as a hangover (Morean et al. 2012, 1009). For example, a university student might be aware of the fact that he or she will have a hangover after a night of so-called ‘clubbing’, but will drink in excess regardless of this knowledge.

Studies of both youths and adults have found empirical evidence that perceived drinking outcomes (i.e. alcohol outcome expectancies), account for substantial amounts of variance in concurrent and longitudinal drinking patterns (Sher, Walitzer, Wood and Brent 1991, 441; 
Stacy, Newcomb and Bentler 1991, 510). Furthermore, perceived drinking outcomes is regarded as a predictor of drinking problems among the youth (Chen, Grube and Madden 1994, 527; Christiansen, Smith, Roehling and Goldman 1989, 97) and young adults (O’Hare 1998, 47). It is suggested that within samples of university students, social alcohol expectancies are among the most salient explanatory factors for drinking outcomes (Young, Connor, Ricciardelli and Saunders 2006, 72). Therefore, it can be concluded that alcohol outcome expectancies has a clear relation to several drinking-related outcomes, and is regarded as a major factor influencing the drinking behaviour of individuals.

Alcohol outcome expectancies have not just been useful in explaining drinking behaviour, but its incorporation into alcohol prevention and intervention programmes has shown promise (Young et al. 2006, 73). Expectancy-based interventions in particular have highlighted the effectiveness of challenging alcohol outcome expectancies to reduce consumption levels (Darkes and Goldman 1998, 74). Given that alcohol outcome expectancies showed associations with drinking initiation and transition from alcohol use to alcohol abuse both cross-sectionally and longitudinally (Aas, Leigh, Anderssen and Jakobsen 1998, 381; Christiansen et al. 1989, 97; Williams and Ricciardelli 1996, 1037), the accurate and reliable assessment of alcohol outcome expectancies is crucial for the early identification of individuals at risk for alcohol abuse and dependence (Leigh 1989, 366). Thus, in theory, the management of alcohol outcome expectancies can be used for both the explanation of behaviour and in the prevention of undesirable behavioural patterns of individuals.

\section{Drinking motives}

The concept of drinking motives is based on the assumption that people drink to obtain certain valued outcomes and can be regarded as the reasons people consume alcohol (Cooper 1994, 117; Cox and Klinger 1988, 170; Kuntsche, Knibbe, Gmel and Engels 2006, 162). Drinking motives thus provide a practical and meaningful avenue to understand the drinking behaviour of individuals (LaBrie, Ehret, Hummer and Prenovost 2012, 379).

Drinking motives have been reported to mediate the relationship between alcohol outcome expectancies and drinking behaviour (Hasking et al. 2011, 485; Kong and Bergman 2010, 859), and is believed to be a more proximal predictor of drinking behaviour than alcohol outcomes expectancies. Theorists regard drinking motives as the final cognitive pathway to alcohol use (Cooper 1994, 127; Cooper, Frone, Russell and Mudar 1995, 1000; Cox and Klinger 1988, 178). The motivation to drink is further regarded as one of the most important - if not the most important - antecedents of drinking behaviour and reflects both personal and environmental 
influences on alcohol use (Cooper 1994, 125; Cooper et al. 1995, 992; Cox and Klinger 1988, 173).

Research on self-reported motives for alcohol consumption indicates that individuals tend to drink for four primary reasons, namely social motives, coping motives, conformity motives and enhancement motives (Cooper 1994, 126; Cooper, Russell, Skinner and Windle 1992, 130; Cox and Klinger 1988, 175). Enhancement motives are internally generated positive reinforcement motives and include drinking to increase or maintain positive affective states, such as feelings of excitement (Cooper 1994, 126; Cooper et al. 1992, 130). Social motives are externally generated positive reinforcement motives and include drinking to achieve certain social goals such as to enjoy social gatherings. Coping motives are internally generated negative reinforcement motives and involves drinking to reduce or avoid negative affective states such as anxiety and depression (Cooper 1994, 118; Cooper et al. 1992, 124; Farber, Khavari and Douglass 1980, 780). Lastly, conformity motives are externally generated negative reinforcement motives and include drinking, for example, to not feel left out of a group (Cooper 1994, 118).

According to Cooper $(1994,120)$, these four drinking motives have proved to be distinct predictors of alcohol use and abuse behaviour. Individuals who drink primarily for coping and enhancement motives have often been associated with heavy drinking, drinking alone, and alcohol-related problems (Cooper 1994, 124; Grant, Stewart, O’Connor, Blackwell and Conrod 2007, 2628; Hasking et al. 2011, 484). Moreover, coping motives have been related to severe problematic drinking (Cooper et al. 1992, 130; McNally, Palfai, Levine and Moore 2003, 1124; Stewart, Zeitlin and Samoluk 1996, 68). Coping motives have been indirectly (by the level of alcohol consumed) and directly (independent of the level of alcohol consumed) been linked to alcohol problems (Cooper 1994, 123; Kassel, Jackson and Unrod 2000, 337; Kuntsche et al. 2006, 166; Simons, Correia and Carey 2000, 157). Of all the drinking motives examined, enhancement motives have most frequently been associated with high alcohol consumption, especially in situations where heavy drinking is encouraged (Cooper 1994, 123; Cooper et al. 1995, 997; Lyvers, Hasking, Hani, Rhodes and Trew 2010, 129).

Social and conformity motives on the other hand are often associated with light, less frequent and non-problematic alcohol consumption (Cooper 1994, 124; Read, Wood, Kahler, Maddock and Palfai 2003, 17). Not surprisingly, social motives are commonly endorsed by drinkers in social circumstances and tend not to be significantly related to heavy drinking or alcohol-related problems (Cooper 1994, 126; Read et al. 2003, 20). Research suggests that social motives are the most commonly cited reasons for alcohol consumption, especially among 
young adults, suggesting that social motives are relatively 'healthy' and provide a 'protective set of reasons for drinking' (Cooper 1994, 126; Cooper et al. 1992, 131; Kuntsche, Knibbe, Gmel and Engels 2005, 851).

\section{Drinking motives as a mediator}

Hasking et al. (2011, 485) assert that drinking motives mediate the relationship between alcohol outcome expectancies and drinking behaviour. The study by Cooper et al. $(1995,991)$ offers an important explanation of the mediating role of drinking motives between alcohol outcome expectancies, affect, and alcohol consumption. Read et al. (2003, 14) replicated the motivational model used by Cooper et al. $(1995,992)$ in a university student population, but expanded the parameters of the study to include social motives as a potential mediator. The results of the study by Read et al. $(2003,17)$ suggested that both social and enhancement motives were strong predictors of alcohol consumption. Furthermore, it was found that social and enhancement motives mediated the relationship between several alcohol outcome expectancies and alcohol consumption. However, although coping motives showed significance to alcohol related problems in cross-sectional analysis, coping motives were not significantly related to either alcohol consumption or alcohol related problems in longitudinal analysis (Read et al. 2003, 20). It is worth considering that drinking to cope may be a less salient predictor of drinking behaviour while at university, during which time social factors and positive affect enhancement may play a more significant role (Read et al. 2003, 21).

The current study explored the relationships between alcohol outcome expectancies, drinking motives, and drinking behaviour among a sample of university students in South Africa. It is hypothesised that alcohol outcome expectancies and drinking motives are directly related to drinking behaviour. It is furthermore hypothesised that the relationship between alcohol outcome expectancies and drinking behaviour is mediated by drinking motives. The hypothesised relationships of the study are illustrated in Figure 1. 


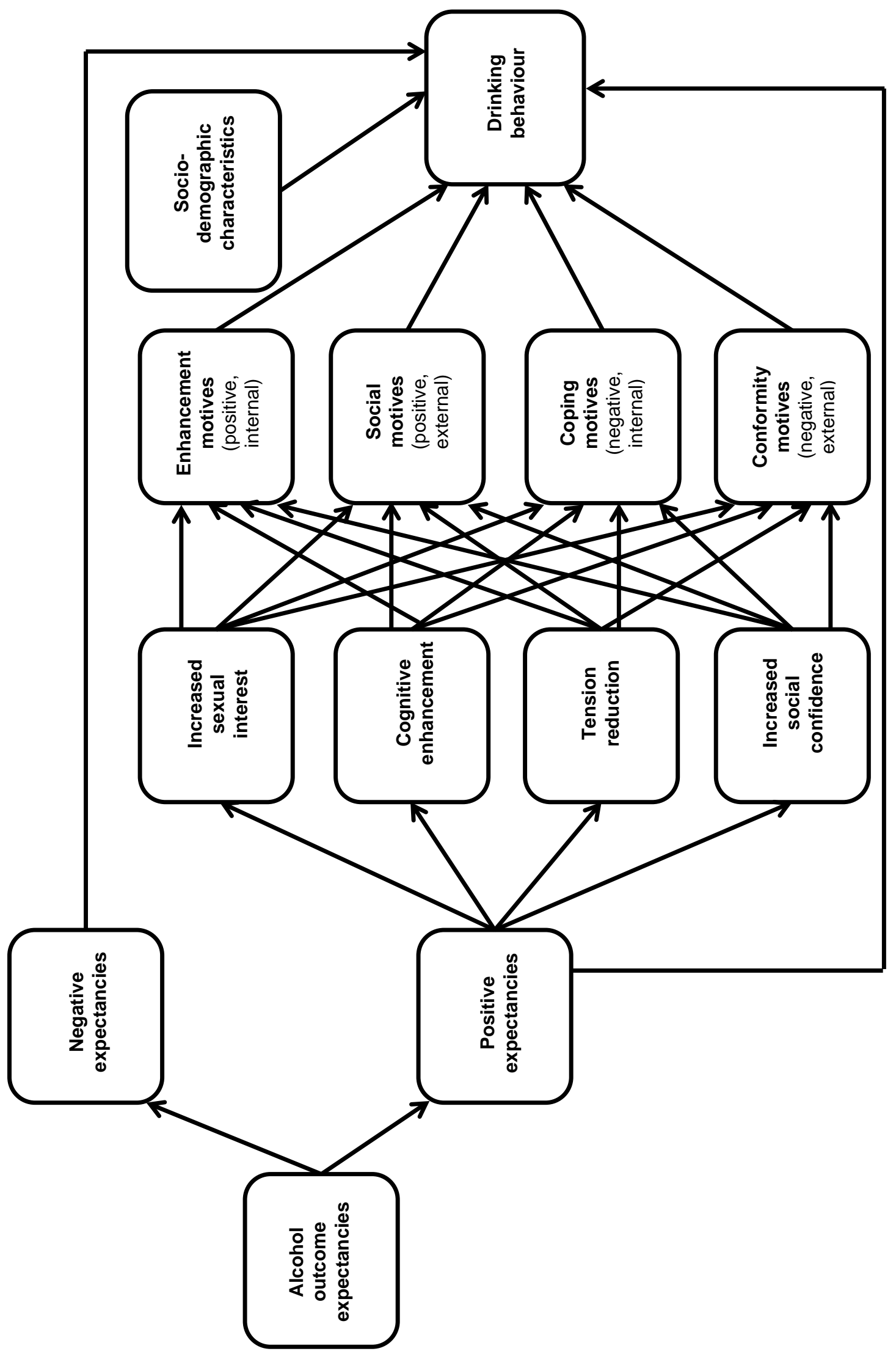

Figure 1: Hypothesised relationships between alcohol outcome expectancies, drinking motives, and drinking behaviour. 


\section{METHODOLOGY}

\section{Sample and data collection}

A convenience sample $(n=474)$ of both undergraduate and postgraduate South African University students was used. The respondents were all South African citizens and frequent drinkers, having consumed alcohol during the preceding 12 months of the study. The data were collected in paper and pencil format after obtaining ethical and institutional clearance.

\section{Measurement instruments}

The Alcohol Use Disorder Identification Test (AUDIT) was used to measure drinking behaviour and is a 10-item Likert type scale designed to identify alcohol consumption, alcohol dependence and problems associated with drinking (Babor, Higgins-Biddle, Saunders and Monteiro 2001, 5). The AUDIT has demonstrated a high degree of internal consistency, yielding a Cronbach's Alpha score of 0.83 , with a range of 0.75 to 0.97 (Reinert and Allen 2007, 186).

The Drinking Expectancies Questionnaire Revised (DEQ-R) was used to measure alcohol outcome expectancies and consists of 37 items loading strongly onto the following five factors: Increased social confidence (12 items), Increased sexual interest (3 items), Cognitive enhancement (3 items), Tension reduction (3 items), and Negative consequences (16). Each item was assessed on a 5-point Likert scale ranging from 1 (Strongly disagree) to 5 (Strongly agree). The DEQ-R instrument has previously been used in studies among university students (Hasking et al. 2011, 481; Li and Dingle 2012, 200), and acceptable psychometric properties were reported.

The Drinking Motives Questionnaire Revised (DMQ-R) is a four-factor, 20-item scale that measures the relative frequency of drinking for Social, Coping, Conformity and Enhancement motives and was used to measure the drinking motives of university students. Each drinking motive dimension was measured by five statements which were rated on a 5point Likert scale ranging from 1 (almost never/never) to 5 (almost always/always). The psychometric properties (validity and reliability) of the DMQ-R have been confirmed as acceptable for use among both adolescent and university student populations (Cooper 1994, 127; Stewart et al. 1996, 63).

Demographic information: Participants completed a questionnaire with information on their age, gender, race, and academic year of study. 


\section{RESULTS AND DISCUSSION}

\section{Drinking behaviour}

The average total AUDIT score that was achieved across the sample was nine. This score is seemingly low when considering that a maximum score of 40 can be achieved. However, nine is an alarmingly high average score as it indicates a pattern of drinking that increases the risk of harmful consequences for the user or others (i.e. hazardous drinking) (Babor et al. 2001, 20). For the purposes of this study, a total AUDIT score of eight (or higher) for males and seven (or higher) for females was regarded as hazardous. According to this classification, 71 per cent of males and 54 per cent of females reported hazardous drinking patterns.

The total AUDIT score can also be used to identify harmful drinking patterns. In this study, harmful drinking was identified by a total AUDIT score of 16 or higher for both males and females, and was defined as a pattern of alcohol consumption that results in consequences for physical and mental health (Babor et al. 2001, 20). Alarmingly, it was found that 13 per cent of the sample indicated harmful drinking behaviour by achieving an AUDIT score of 16 or higher. The total AUDIT score can furthermore be used to identify those individuals who are causing definite harm to themselves and who are most likely alcohol dependent. A total AUDIT score of 20 or higher for both males and females was used to identify these high-risk individuals. Disconcertingly, 6.75 per cent of the respondents fell in this category.

Lastly, the total AUDIT score was used to measure the binge drinking behaviour of university students. For the purpose of the present study, the WHO's definition of binge drinking was used. According to the WHO, binge drinking refers to those individuals (15 years or older) who consume at least 60 grams or more of pure alcohol at least once a week (this corresponds to approximately six standard alcoholic drinks or units of alcohol). A total of 18.78 per cent of university students indicated binge drinking patterns or heavy episodic drinking. Additional alcohol-related questions revealed that students mostly drink on Fridays and Saturdays, at bars and clubs between the hours of 18:00 and 24:00 with their university friends. Furthermore, the most preferred beverage among university students was wine (also when drinking at home or at a restaurant). Bars and clubs were the only places where hard liquor was their beverage of choice.

\section{Partial least squares analysis (PLS)}

Partial least squares modelling was conducted to explore the relationships between alcohol outcome expectancies, drinking motives, and drinking behaviour. A two-stage approach to 
analyse and report PLS modelling was followed, as proposed by Chin (2010, 669).

\section{Stage one: Measurement model results}

To examine the internal consistency of the measures, the composite reliability developed by Werts, Linn and Joreskog (1974) was calculated for each of the latent variables. The model under examination was confirmatory in nature and as a result, composite reliability scores of $\geq$ 0.7 were deemed appropriate (Götz, Liehr-Gobbers and Krafft 2010, 695; Hair, Ringle and Sarstedt 2011, 145). Composite reliability scores in the present study ranged from 0.727 to 0.926, indicating sufficient internal consistency among the measures used to represent the latent variables. As a supplementary measure of internal consistency, Cronbach’s alpha scores were calculated which ranged from 0.752 to 0.911 , providing supporting evidence for the composite reliability scores reported above.

The outer loadings of the measurement model indicated that all items reliably represented the variables that they were supposed to measure, with the exception of three items measuring cognitive enhancement (which was an alcohol outcome expectancy factor). Closer inspection revealed that cognitive enhancement was not significantly related to any latent variable assessed in the empirical model which postulated that the lack of correlation may be partially due to the items in the measurement instrument used to measure cognitive enhancement (i.e. measurement error).

To estimate convergent validity, the Average Variance Extracted (AVE) suggested by Fornell and Larcker (1981, 45), was calculated and the proposed value of 0.50 by Chin (2010, 671) was used as a guideline to determine convergent validity. Results for all variables yielded a score of 0.50 or more with two exceptions; negative consequences and drinking behaviour. Drinking behaviour, the latent dependent variable, achieved an AVE score of 0.437. This implies that the convergent validity of the items that were used to measure drinking behaviour was questionable due to measurement error. However, the AVE score of drinking behaviour was not low enough to cause alarm and was thus regarded as adequate for the purpose of this study. On the other hand, the AVE score of the negative consequences was alarmingly low at 0.328, pointing to weak convergent validity. Overall, the AVE scores were acceptable, indicating sufficient convergent validity. Discriminant validity was inferred using the FornellLarcker criterion (Fornell and Larcker 1981, 46) and the results show adequate discriminant validity for all measures in the model. Multicollinearity was not regarded as an issue in this study as the Variance Inflation Factor (VIF) ranged from 1.056 to 2.421 which was below the acceptable limit of 5.0. The measurement model demonstrated sufficient robustness to proceed 
to stage two which involved exploring the relationships between the exogenous and endogenous variables.

\section{Stage two: Structural model results}

The second stage of PLS modelling consists of the evaluation of the structural model using the bootstrap resampling method (Chin 2010, 674). The causal structure of the model was assessed by computing the coefficient of determination (R2) and path coefficients to examine the effects among the latent variables. The complete model was able to explain 49.4 per cent of the variance in drinking behaviour, 27.2 per cent in social motives, 24.9 per cent in coping motives, 29.8 per cent in enhancement motives and a mere 8.7 per cent in conformity motives. It can therefore be posited that by considering alcohol outcome expectancies and drinking motives only, approximately 50 per cent of the variance in the drinking behaviour of university students represented in this sample can be explained. The remaining 50 per cent of variance in drinking behaviour could be explained by variables external to the hypothesised model.

The present study followed the bootstrapping re-sampling procedure which provides confidence intervals to determine significant relationships between the variables in the model (Henseler, Ringle and Sinkovics 2009, 305). More than half of the proposed relationships showed significance at $\mathrm{p}<0.05$. The relationships among alcohol outcome expectancies, drinking motives, and drinking behaviour are illustrated in Figure 2. The majority of the outcome expectancy variables were inter-correlated in the expected directions. Of the five alcohol outcome expectancy factors assessed, increased sexual interest, tension reduction, and negative consequences were positively correlated with drinking behaviour as measured by the AUDIT. However, the analysis failed to observe significant relationships between increased social confidence and drinking behaviour, and between cognitive enhancement and drinking behaviour.

In terms of the positive outcome expectancies, the results of the structural model indicate that university students expected their level of sexual interest to increase when consuming alcohol. In addition, they expected an element of tension reduction or stress relief when drinking. These findings are consistent with prevailing literature confirming a relationship between positive outcome expectancies and drinking behaviour (Brown et al. 1985, 516; Hasking et al. 2011, 483). The positive relationship between drinking behaviour and increased sexual interest could be expected among university students who are in their prime sexual age. Research also indicates a positive relationship between increased sexual activity and drinking behaviour (Graves and Leigh 1995, 20) suggesting that increased sexual interest might translate 
into sexual behaviour among university students when drinking.

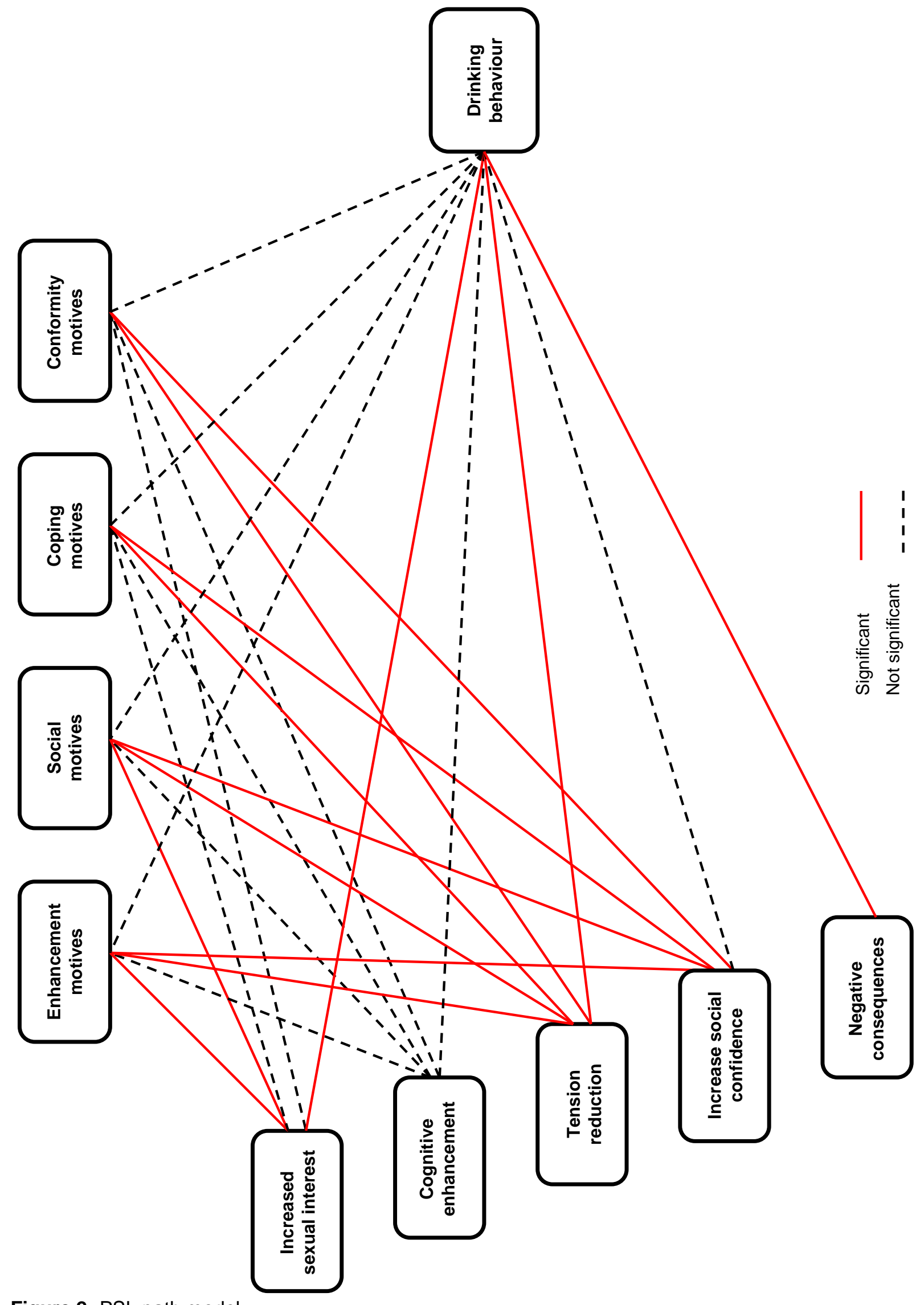

Figure 2: PSL path model

The fact that university students expected an element of tension reduction when drinking 
can be attributed to the high levels of stress that university students experience while studying at a university. Thus, although university students might not drink for the primary reason to cope with stress, they might expect an element of stress relief when drinking.

This study failed to observe a relationship between increased social confidence and drinking behaviour, neither did university students expect intellectual enhancement when drinking. A possible explanation is that university students consume alcohol with their friends in social situations where they feel comfortable. In other words, they do not feel the need for alcohol to boost their confidence or cognitive functioning, and consequently, do not expect the mentioned outcomes when consuming alcohol.

Another notable result is the fact that cognitive enhancement was not significantly related to any other variable in the hypothesised model. This null finding could be attributed to measurement error. However, a further explanation could be that university students do not expect their cognitive abilities to increase when consuming alcohol as they already feel comfortable in situations where they consume alcohol. Providing further support for this finding, Hasking et al. (2011, 483) made a similar observation among undergraduate Australian university students.

Shifting the focus to negative outcome expectancies, a positive relationship was observed between negative outcome expectancies and drinking behaviour, which is contradictory to several research studies (Fromme and D’Amico 2000, 209; Hasking and Oei 2007, 109; Jones et al. 2001, 60; Pabst et al. 2010, 51) while, on the other hand, concur with a number of others (Greenfield et al. 2009, 83; Hasking et al. 2011, 484; Morean et al. 2012, 15). In essence, people who consume high levels of alcohol and drink in a riskier manner are more likely to experience negative consequences as a result of their drinking (Morean et al. 2012, 15). They are thus more likely to report anticipating negative consequences, which explains the positive relationship between negative consequences and drinking behaviour. It can therefore be argued that university students are knowledgeable individuals who understand the effects of alcohol consumption. This knowledge could stem from personal experience, and education about the harmful consequences of alcohol from their parents, schools and churches, for example. In similar vein, this acquired knowledge does not necessarily function as a barrier to excessive drinking.

In terms of drinking motives, the present study observed social and enhancement motives as predictors of drinking behaviour among university students, but failed to find a link between coping and conformity motives and drinking behaviour. It was established that university students in the present study mostly used alcohol to achieve social goals such as to experience 
increased levels of enjoyment of social gatherings (i.e. social motives) and to increase or maintain positive affective states, such as feelings of excitement or joy (i.e. enhancement motives). Previous research on self-reported drinking motives also support the present study's findings of a positive relationship between social and enhancement motives and drinking behaviour. (Cooper 1994, 123; Cooper et al. 1992, 128; Hasking et al. 2011, 483).

The results did not, however, indicate a relationship between coping motives and drinking behaviour and neither between conformity motives and drinking behaviour. Put differently, students in this sample did not drink to reduce or avoid negative affective states such as anxiety and depression (i.e. coping motives) nor did they drink not to feel left out of a group (i.e. conformity motives). The fact that a positive relationship was found between tension reduction and drinking behaviour, but not between coping motives and drinking behaviour is seemingly counter-intuitive, however, a logical explanation exists for this phenomenon: Read et al. (2003, 21) noted that drinking to cope may be a less salient predictor of drinking behaviour while at university, during which time social factors and positive affect enhancement play a greater role. Therefore, although university students might expect an element of tension reduction when consuming alcohol due the stress they experience in their daily lives, they might not necessarily drink for the primary reason of reducing tension.

With regard to conformity motives, the current study's findings concur with those of Lyvers et al. (2010, 120), who reported that conformity motives were not strong predictors of either alcohol consumption or alcohol-related problems, However, considering the central role that peer groups play in the behaviour of university students, the null finding between conformity motives and drinking behaviour is perplexing. A possible explanation is that university students conform to and follow group norms without realising that they have conformed to a group's behaviour (Epley and Gilovich 1999, 586) (i.e. unconscious conformation). Therefore, the sample population might have conformed to the groups that they were part of in terms of drinking behaviour, but they did not report this conformity as they were unaware of it.

The PLS analysis further considered the mediational role (that is, no mediation, partial mediation or full mediation) that each drinking motive play in the association between positive alcohol outcome expectancies and drinking behaviour. To provide ancillary evidence for the mediational effects determined by the bootstrapping resampling method, the Sobel test was conducted on each of the relationships.

Neither coping motives nor conformity motives were significantly related to drinking behaviour, and as a result, positive alcohol outcome expectancies could not be mediated by 
these motives. However, both social and enhancement motives mediated the influence of several alcohol outcome expectancies on drinking behaviour. The effect of increased social confidence on drinking behaviour was fully mediated by social and enhancement motives. Furthermore, the influence of both increased sexual interest and tension reduction on drinking behaviour was partially mediated by both social and enhancement motives. The overall strength of these mediated pathways supports a growing body of literature suggesting that the relationship between alcohol outcome expectancies and drinking behaviour is mediated by drinking motives (Carrigan, Ham, Thomas and Randall 2008, 1164; Galen, Henderson and Coovert 2001, 211; Greenfield et al. 2009, 83; Kuntsche, Knibbe, Engels and Gmel 2007, 83; Kuntsche, Wiers, Janssen and Gmel 2010, 440). Therefore, it can be argued that drinking motives play a vital role in mediating the effect of positive alcohol outcome expectancies on drinking behaviour.

Although a direct relationship between increased social confidence and drinking behaviour was not observed, the results indicate that increased social confidence indirectly influences drinking behaviour by means of social and enhancement motives. Therefore, students who need more confidence in social situations may be motivated by social and enhancement reasons for drinking (Hasking et al. 2011, 485). For example, a student who is shy in social situations and need confidence to strengthen his or her enjoyment of social interaction, might be motivated to drink.

Furthermore, a direct relationship between tension reduction and drinking behaviour was observed, but this relationship was also partially mediated by social and enhancement motives. It is therefore postulated that when students consume alcohol in social situations and drink for social and enhancement reasons, they may expect an element of tension reduction. This may particularly be true for students who suffer from social anxiety (Booth and Hasking 2009, 735). However, this suggestion was not explored in the current study.

Lastly, expectations of sexual enhancement were related to both social and enhancement motives which, in turn, influenced drinking behaviour. This finding implies that the DMQ-R did not tap into all the motives for drinking and that there are other reasons including sexual motives, for drinking. However, from the current findings it can be argued that students who expect that alcohol consumption will enhance their sexual interest, may be motivated to drink to achieve such an effect. Given that the majority of expectancy research does not delineate between specific expectancies (Pabst et al. 2010, 52), future research is required to fully explore the relationships between specific expectancies and specific motives. 


\section{CONCLUSIONS AND MANAGERIAL RECOMMENDATIONS}

The results of this study may assist the public health authorities to better understand the drinking behaviour of young adults, especially university students. It may also enable the authorities to design and implement more effective alcohol policies, alcohol abuse prevention and education programmes targeted at this group of individuals.

Alcohol abuse prevention and education campaigns targeted at university students such as the responsible drinking campaigns Get Home Safe of Rhodes University and Stellenbosch University's Buddy campaign should take drinking motives and alcohol outcome expectancies into account when marketing campaigns against excessive alcohol consumption are designed. People responsible for such campaigns should incorporate and emphasise social and enhancement drinking motives by, for instance, considering the approach of Educ'alcool, a nonprofit organisation in the Quebec province of Canada. Educ'alcool promotes moderate and healthy drinking while, at the same time, discourages excessive drinking. Furthermore, people responsible for alcohol abuse prevention and education campaigns should use social and enhancement motives to position their campaigns in such a way that it resonates with university students. For example, messages should communicate that severe drinking among young people in social situations is socially unacceptable, while the same messages should promote responsible drinking in moderation (e.g. enjoying a glass of wine with friends). This approach could be more effective than focussing on the negative consequences of excessive alcohol consumption (e.g. a hangover) because negative outcomes have proved not to deter students from drinking excessively. Responsible drinking campaigns can rather illustrate how the consumption of a small amount of alcohol can lead to the reduction of tension, and the enjoyment of social gatherings. To summarise, responsible drinking campaigns aimed at students should foster a culture of moderate consumption of alcohol, while at the same time depicting excessive consumption as socially unacceptable.

\section{LIMITATIONS AND SUGGESTIONS FOR FUTURE RESEARCH}

Notwithstanding the useful contributions of this study, several limitations should be noted of which convenience sampling and the size of the sample is evident, limiting the generalisability of the results. The correlational design further precludes inferences about the causal relationships between the variables investigated. The present study also only included the most proximal predictors of drinking behaviour resulting in only 49.4 per cent of the variance explained in drinking behaviour. There are variables that may also influence the drinking behaviour of university students other than those assessed in this study. 
It is suggested that researchers address these limitations, and furthermore test a more comprehensive model of the antecedents of drinking behaviour. The question why students drink remains complex, and calls for more research to, amongst others, ensure the development of scientifically sound responsible drinking campaigns.

Finally, it is hoped that the present study will stimulate continued research among the academic community into the drinking behaviour of South African university students. More specifically in-depth studies into the high-risk group of drinkers are recommended.

\section{REFERENCES}

Aas, H. N., B. C. Leigh, N. Anderssen and R. Jakobsen. 1998. Two-year longitudinal study of alcohol expectancies and drinking among Norwegian adolescents. Addiction 93(3): 373-384.

Agrawal, A., D. M. Dick, K. K. Bucholz, P. A. F. Madden, M. L. Cooper, K. J. Sher and A. C. Heath. 2008. Drinking expectancies and motives: A genetic study of young adult women. Addiction 103(2): 194-204.

Babor, T. F., J. C. Higgins-Biddle, J. B. Saunders and M. G. Monteiro. 2001. The alcohol use disorders identification test: Guidelines for use in primary care. http://whqlibdoc.who.int/ hq/2001/who_msd_msb_01.6a.pdf (accessed 20 February 2014).

Bandura, A. 1977. Social learning theory. http://www.asecib.ase.ro/mps/Bandura_SocialLearning Theory.pdf (accessed 20 February 2014).

Booth, C. and P. Hasking. 2009. Social anxiety and alcohol consumption: The role of alcohol expectancies and reward sensitivity. Addictive Behaviors 34(9): 730-736.

Brown, S. A., M. S. Goldman and B. A. Christiansen. 1985. Do alcohol expectancies mediate drinking patterns of adults? Journal of Consulting and Clinical Psychology 53(4): 512-519.

Carrigan, M. H., L. S. Ham, S. E. Thomas and C. L. Randall. 2008. Alcohol outcome expectancies and drinking to cope with social situations. Addictive Behaviors 33(9): 1162-1166.

Chen, M. J., J. W. Grube and P. A. Madden. 1994. Alcohol expectancies and adolescent drinking: Differential prediction of frequency, quantity, and intoxication. Addictive Behaviors 19(5): 521529.

Chin, W. W. 2010. How to write up and report PLS analyses. In Handbook of partial least squares: Concepts, methods and applications in marketing and related fields, ed. V. E. Vinzi, W. W. Chin, J. Henseler and H. Wang, 655-690. Berlin: Springer.

Christiansen, B. A., G. T. Smith, P. J. Roehling and M. S. Goldman. 1989. Using alcohol expectancies to predict adolescent drinking behavior after one year. Journal of Consulting and Clinical Psychology 57(1): 93-99.

Cooper, M. L. 1994. Motivations for alcohol use among adolescents: Development and validation of a four-factor model. Psychological Assessment 6(2): 117-128.

Cooper, M. L., M. R. Frone, M. Russell and P. Mudar. 1995. Drinking to regulate positive and negative emotions: A motivational model of alcohol use. Journal of Personality and Social Psychology 69(5): 990-1005.

Cooper, M. L., M. Russell, J. B. Skinner and M. Windle. 1992. Development and validation of a threedimensional measure of drinking motives. Psychological Assessment 4(2): 123-132.

Cox, W. M. and E. Klinger. 1988. A motivational model of alcohol use. Journal of Abnormal Psychology 97(2): 168-180.

Darkes, J. and M. S. Goldman. 1998. Expectancy challenge and drinking reduction: Process and 
structure in the alcohol expectancy network. Experimental and Clinical Psychopharmacology 6(1): 64-76.

Epley, N. and T. Gilovich. 1999. Just going along: Nonconscious priming and conformity to social pressure. Journal of Experimental Social Psychology 35(6): 578-589.

Farber, P. D., K. A. Khavari and F. M. Douglass. 1980. A factor analytic study of reasons for drinking: Empirical validation of positive and negative reinforcement dimensions. Journal of Consulting and Clinical Psychology 48(6): 780-781.

Fornell, C. and D. F. Larcker. 1981. Evaluating structural equation models with unobservable variables and measurement error. Journal of Marketing Research 18(1): 39-50.

Fromme, K. and E. J. D’Amico. 2000. Measuring adolescent alcohol outcome expectancies. Psychology of Addictive Behaviors 14(2): 206-212.

Galen, L. W., M. J. Henderson and M. D. Coovert. 2001. Alcohol expectancies and motives in a substance abusing male treatment sample. Drug and Alcohol Dependence 62(3): 205-214.

Germishuys, G. 2015. Zero alcohol limit: How you'll be hit. http://www.wheels24.co.za/News/SA-0alcohol-limit-How-youll-be-hit-20150204 (accessed 9 July 2015).

Global Status Report on Alcohol and Health. 2011. http://www.who.int/substance_abuse/publications/ global_alcohol_report/msbgsruprofiles.pdf (accessed 15 December 2013).

Global Status Report on Alcohol and Health. 2014. http://www.who.int/substance_abuse/publications/ global_alcohol_report/msb_gsr_2014_1.pdf?ua=1 (accessed 25 June 2014).

Goldman, M. S., F. K. Del Boca and J. Darkes. 1999. Alcohol expectancy theory: The application of cognitive neuroscience. In Psychological theories of drinking and alcoholism, ed. Kenneth E. Leonard and Howard T. Blane, 203-246. New York. The Guilford Press.

Götz, O., K. Liehr-Gobbers and M. Krafft. 2010. Evaluation of structural equation models using the partial least squares (PLS) approach. In Handbook of partial least squares: Concepts, methods and applications in marketing and related fields, ed. V. E. Vinzi, W. W. Chin, J. Henseler and H. Wang, 691-711. Berlin: Springer.

Grant, V. V., S. H. Stewart, R. M. O’Connor, E. Blackwell and P. J. Conrod. 2007. Psychometric evaluation of the five-factor Modified Drinking Motives Questionnaire - Revised in undergraduates. Addictive Behaviors 32(11): 2611-2632.

Graves, K. L. and B. C. Leigh. 1995. The relationship of substance use to sexual activity among young adults in the United States. Family Planning Perspectives 27(1): 18-33.

Greenfield, T. K., T. C. Harford and T. W. Tam. 2009. Modeling cognitive influences on drinking and alcohol problems. Journal of Studies on Alcohol and Drugs 70(1): 78-86.

Hair, J. F., C. M. Ringle and M. Sarstedt. 2011. PLS-SEM: Indeed a silver bullet. Journal of Marketing Theory and Practice 19(2): 139-151.

Hasking, P., M. Lyvers and C. Carlopio. 2011. The relationship between coping strategies, alcohol expectancies, drinking motives and drinking behaviour. Addictive Behaviors 36(5): 479-487.

Hasking, P. A. and T. P. Oei. 2007. Alcohol expectancies, self-efficacy and coping in an alcoholdependent sample. Addictive Behaviors 32(1): 99-113.

Henseler, J., C. M. Ringle and R. R. Sinkovics. 2009. The use of partial least squares path modeling in international marketing. In New challenges to international marketing, ed. R. R. Sinkovics and P. N. Ghauri, 277-319. Emerald Group Publishing Limited.

Hingson, R. W., W. Zha and E. R. Weitzman. 2009. Magnitude of and trends in alcohol-related mortality and morbidity among US college students ages 18-24, 1998-2005. Journal of Studies on Alcohol and Drugs 16: 12-20.

Jones, B. T., W. Corbin and K. Fromme. 2001. A review of expectancy theory and alcohol consumption. Addiction 96(1): 57-72.

Kassel, J. D., S. I. Jackson and M. Unrod. 2000. Generalized expectancies for negative mood regulation 
and problem drinking among college students. Journal of Studies on Alcohol and Drugs 61(2): 332-340.

Kilbey, M. M., K. Downey and N. Breslau. 1998. Predicting the emergence and persistence of alcohol dependence in young adults: The role of expectancy and other risk factors. Experimental and Clinical Psychopharmacology 6(2): 149-156.

Kong, G. and A. Bergman. 2010. A motivational model of alcohol misuse in emerging adulthood. Addictive Behaviors 35(10): 855-860.

Kuntsche, E., R. Knibbe, R. Engels and G. Gmel. 2007. Drinking motives as mediators of the link between alcohol expectancies and alcohol use among adolescents. Journal of Studies on Alcohol and Drugs 68(1): 76-85.

Kuntsche, E., R. Knibbe, G. Gmel and R. Engels. 2005. Why do young people drink? A review of drinking motives. Clinical Psychology Review 25(7): 841-861.

Kuntsche, E., R. Knibbe, G. Gmel and R. Engels. 2006. Replication and validation of the Drinking Motive Questionnaire Revised (DMQ-R, Cooper 1994) among adolescents in Switzerland. European Addiction Research 12(3): 161-168.

Kuntsche, E., R. W. Wiers, T. Janssen and G. Gmel. 2010. Same wording, distinct concepts? Testing differences between expectancies and motives in a mediation model of alcohol outcomes. Experimental and Clinical Psychopharmacology 18(5): 436-444.

Kypri, K. Y. P., M. Cronin and C. S. Wright. 2005. Do university students drink more hazardously than their non-student peers? Addiction 100(5): 713-714.

LaBrie, J. W., P. J. Ehret, J. F. Hummer and K. Prenovost. 2012. Poor adjustment to college life mediates the relationship between drinking motives and alcohol consequences: A look at college adjustment, drinking motives, and drinking outcomes. Addictive Behaviors 37(4): 379-386.

Leigh, B. C. 1989. In search of the Seven Dwarves: Issues of measurement and meaning in alcohol expectancy research. Psychological Bulletin 105(3): 361-373.

Li, H. K. and G. A. Dingle. 2012. Using the Drinking Expectancy Questionnaire (revised scoring method) in clinical practice. Addictive Behaviors 37(2): 198-204.

Lyvers, M., P. Hasking, R. Hani, M. Rhodes and E. Trew. 2010. Drinking motives, drinking restraint and drinking behaviour among young adults. Addictive Behaviors 35(2): 116-122.

McNally, A. M., T. P. Palfai, R. V. Levine and B. M. Moore. 2003. Attachment dimensions and drinking-related problems among young adults: The mediational role of coping motives. Addictive Behaviors 28(6): 1115-1127.

Morean, M. E., T. A. Treat and W. R. Corbin. 2012. The anticipated effects of alcohol scale: Development and psychographic evaluation of a novel assessment tool for measuring alcohol expectancies. Psychological Assessment 24(4): 1008-1023.

O’Hare, T. 1998. Alcohol expectancies and excessive drinking contexts in young adults. Social Work Research 22(1): 44-50.

Pabst, A., S. E. Baumeister and L. Kraus. 2010. Alcohol-expectancy dimensions and alcohol consumption at different ages in the general population. Journal of Studies on Alcohol and Drugs 71(1): 46-53.

Pastor, A. D. and S. M. Evans. 2003. Alcohol outcome expectancies and risk for alcohol use problems in women with and without a family history of alcoholism. Drug and Alcohol Dependence 70(2): 201-214.

Peltzer, K., A. Davids and P. Njuho. 2011. Alcohol use and problem drinking in South Africa: Findings from a national population-based survey. African Journal of Psychiatry 14(1): 30-37.

Read, J. P., M. D. Wood, C. W. Kahler, J. E. Maddock and T. P. Palfai. 2003. Examining the role of drinking motives in college student alcohol use and problems. Psychology of Addictive Behaviors 17(1): 13-23. 
Reinert, D. F. and J. P. Allen. 2007. The alcohol use disorders identification test: An update of research findings. Alcoholism: Clinical and Experimental Research 31(2): 185-199.

SAPA, see South African Press Association.

South African Press Association. 2013. Cabinet approves bill banning alcohol ads. http://www.bizcommunity.com/Article/ 196/12/100595.html (accessed 9 July 2015).

Schneider, M., R. Norman, C. Parry, D. Bradshaw, A. Pluddemann and South African Comparative Risk Assessment Collaboration. 2007. Estimating the burden of disease attributable to alcohol use in South Africa in 2000. South African Medical Journal 97(8): 664-672.

Schuckit, M. A. and T. L. Smith. 2001. A comparison of correlates of DSM-IV alcohol abuse or dependence among more than 400 sons of alcoholics and controls. Alcoholism: Clinical and Experimental Research 25(1): 1-8.

Sher, K. J., K. S. Walitzer, P. K. Wood and E. E. Brent. 1991. Characteristics of children of alcoholics: Putative risk factors, substance use and abuse, and psychopathology. Journal of Abnormal Psychology 100(4): 427-448.

Simons, J., C. J. Correia and K. B. Carey. 2000. A comparison of motives for marijuana and alcohol use among experienced users. Addictive Behaviors 25(1): 153-160.

Stacy, A. W., M. D. Newcomb and P. M. Bentler. 1991. Cognitive motivation and drug use: A 9-year longitudinal study. Journal of Abnormal Psychology 100(4): 502-515.

Stewart, S. H., S. B. Zeitlin and S. B. Samoluk. 1996. Examination of a three-dimensional drinking motives questionnaire in a young adult university student sample. Behaviour Research and Therapy 34(1): 61-71.

Werts, C. E., R. L. Linn and K. G. Jöreskog. 1974. Intraclass reliability estimates: Testing structural assumptions. Educational and Psychological Measurement 34(1): 25-33.

Williams, R. J. and L. A. Ricciardelli. 1996. Expectancies relate to symptoms of alcohol dependence in young adults. Addiction 91(7): 1031-1039.

Young, R. M. and T. P. S. Oei. 1993. Grape expectations: The role of alcohol expectancies in the understanding and treatment of problem drinking. International Journal of Psychology 28(3): 337-364.

Young, R. M., J. P. Connor, L. A. Ricciardelli and J. B. Saunders. 2006. The role of alcohol expectancy and drinking refusal self-efficacy beliefs in university student drinking. Alcohol and Alcoholism 41(1): 70-75. 